\title{
Information, prices and efficiency in an online betting market
}

Article

Accepted Version

Creative Commons: Attribution-Noncommercial-No Derivative Works 4.0

Elaad, G., Reade, J. and Singleton, C. (2020) Information, prices and efficiency in an online betting market. Finance Research Letters, 35. 101291. ISSN 1544-6123 doi: https://doi.org/10.1016/j.frl.2019.09.006 Available at https://centaur.reading.ac.uk/86111/

It is advisable to refer to the publisher's version if you intend to cite from the work. See Guidance on citing.

To link to this article DOI: http://dx.doi.org/10.1016/j.frl.2019.09.006

Publisher: Elsevier

All outputs in CentAUR are protected by Intellectual Property Rights law, including copyright law. Copyright and IPR is retained by the creators or other copyright holders. Terms and conditions for use of this material are defined in the End User Agreement.

\section{www.reading.ac.uk/centaur}

\section{CentAUR}

Central Archive at the University of Reading

Reading's research outputs online 


\title{
Information, prices and efficiency in an online betting market
}

\author{
Guy Elaad \\ Ariel University \\ J. James Reade \\ University of Reading \\ Carl Singleton* \\ University of Reading
}

Accepted: Finance Research Letters. (2019).

\begin{abstract}
We contribute to the discussion on betting market efficiency by studying the odds (or prices) set by fifty-one online bookmakers, for the result outcomes in over 16,000 association football matches in England since 2010. Adapting a methodology typically used to evaluate forecast efficiency, we test the Efficient Market Hypothesis in this context. We find odds are generally not biased when compared against actual match outcomes, both in terms of favourite-longshot or outcome types. But individual bookmakers are not efficient. Their own odds do not appear to use fully the information contained in their competitors' odds.
\end{abstract}

Keywords: prediction markets, Efficient Market Hypothesis, favourite-longshot bias, forecast efficiency

*guyel@ariel.ac.il; Department of Economics and Business Management, Ariel University, P.O. Box 3, 40700, Ariel, Israel

j.j.reade@ @ reading.ac.uk, Department of Economics, University of Reading, Whiteknights Campus, RG6 6UA, UK.

Corresponding author: c.a.singleton@reading.ac.uk, Department of Economics, University of Reading, whiteknights Campus, RG6 6UA, UK.

Singleton is supported by the Economic and Social Research Council (UK) under Grant No. ES/J500136/1. 


\section{Introduction}

Betting markets have long been viewed as a testing ground for Fama's 1970 Efficient Market Hypothesis (henceforth EMH; e.g. Thaler and Ziemba, 1988). Participants in these markets are knowledgeable and motivated, and information is timely, reliable, widely available at next to no cost, and straightforward to interpret. In theory, this informational efficiency should imply betting odds, or prices, supply accurate forecasts of future outcomes. Testing the EMH should be more straightforward in betting markets than in typical financial markets because there is a fixed time when a bet's value is revealed, i.e. when an event ends. There are other particular features of betting markets, most relevant being the nature of bookmakers to exploit systematically biases among their customers (Kuypers, 2000; Levitt, 2004). If this is the case, then odds could in fact imply inefficient forecasts.

We study the online betting market for 16,000 English professional football match results between 2010 and 2018. We chose this market since there are many bookmakers providing odds over several years, and this data is readily available, meaning any findings should not be driven by some narrow period or specific bookmaker. It is also a high volume betting market, with millions of British pounds $(\mathfrak{f})$ traded on individual match results at the most prominent exchanges.

Despite a literature looking at the topic of efficiency in these betting markets (e.g. Goddard and Asimakopoulos, 2004; Vlastakis et al., 2009), there are few studies formally testing whether prices for home-draw-away result outcomes are efficient. Pope and Peel (1989) studied the odds for English matches in 1981/82 from four high-street bookmakers, finding some evidence of inefficiency, in particular for the draw outcome. Kuypers (2000) similarly found evidence of inefficiency by studying the odds from one bookmaker on English matches in 1993/95, and Reade (2014) did for the top five divisions in English football between 2011 and 2014. Angelini and De Angelis (2019) studied a larger sample of matches and sources of online odds for results in the top tiers of eleven European leagues. They tested market efficiency by adapting the Mincer and Zarnowitz (1969) forecast evaluation framework, asking whether average market prices for home and away wins deviate from efficiency due to a favourite-longshot bias. They found different degrees of efficiency across markets. We extend this approach by modelling the heterogeneity between bookmakers in their profit margins and considering whether odds also imply too few drawn (tied) matches; Angelini and De Angelis (2019) only used average bookmaker odds and did not analyse the draw outcome. We test for a version of semi-strong efficiency, i.e. whether there is any significant opportunity for bettors to do better on average than just losing the bookmaker's profit margin because of some predictable bias in the odds. We also check for differences in efficiency between the tiers of 
English football, since in the lower leagues competition in the online market is less, the volume of money staked is lower and the bettors are likely to be more informed.

\section{Method}

Let $y_{i}$ equal one if some combination of match and outcome result (home win, draw or away win) happened and zero otherwise, where $i=1, \ldots, I$. Let $p_{i j}$ be the unobserved beliefs of bookmaker $j=1, \ldots, J$ about the probability of $y_{i}$ happening beforehand. The bookmaker gives decimal odds $o_{i j}$ on the outcome, meaning that on taking a $£ 1$ bet they return $o_{i j}$ to the bettor if the outcome happens and gain $£ 1$ if it does not. Let $z_{i j}=1 / o_{i j}$ be the inverse odds or implied odds-based probability forecast of the bookmaker. For any match, summing $z_{i j}$ over the three possible outcomes will give a value greater than one, which reflects the bookmaker's expected rate of commission or profit margin $\kappa_{j}$, also known as the 'overround' or 'vig'. This implies $z_{i j}=p_{i j}+\kappa_{j}$. If we denote $\varepsilon_{i j}=y_{i j}-z_{i j}$, then an efficient bookmaker-specific market requires $E_{i}\left[\varepsilon_{i j}\right]=-\kappa_{j}$. In other words, the market is efficient if the bookmaker makes some average level of commission across matches and outcomes, and no other information can predict $\varepsilon_{i j}$, since it will already be priced into the odds.

We consider two general departures from the EMH in a betting market. First, we ask whether the odds systematically over- or under-predict any particular result. There is evidence that individuals tend to under-predict significantly the draw outcome of football matches, which is consistent with the psychological concept of splitting, or 'black and white' thinking (e.g. Na et al., 2018). Second, there is an empirical irregularity in some prediction markets known as the favourite-longshot bias, whereby odds appear to underestimate the chances of the most (least) expected outcomes over the least (most), making bets on favourites more profitable than on longshots or vice versa (see summary by Ottaviani and Sørensen, 2008).

We test whether betting markets are efficient by adapting the standard Mincer and Zarnowitz (1969) forecast efficiency evaluation framework further than Angelini and De Angelis (2019), estimating the following model using least squares:

$$
\varepsilon_{i j}=\beta_{h} h_{i j}+\beta_{a} a_{i j}+\beta_{z} z_{i j}+\phi_{t(i j)}+\alpha_{j}+v_{i j}, \quad E\left[v_{i j} \mid h_{i j}, a_{i j}, z_{i j}, \phi_{t}, \alpha_{j}\right]=0,
$$

where $h_{i j}$ and $a_{i j}$ are dummy variables indicating whether the odds are for a home or away win. To address heterogeneity in the bookmaker margins and how this might be correlated with their tendency to reflect a favourite-longshot bias in their odds, $\alpha_{j}$ give bookmaker fixed effects. We address whether these margins have in general changed by estimating season fixed effects in $\phi_{t(i j)}$, where $t(i j)$ indicates the season when a match took place. The remaining heterogeneity 
is left in the residual term $v_{i j}$. We estimate (1) using weighted least squares, thus increasing efficiency and partially addressing heteroskedasticity in the forecast errors. The elements of the diagonal weighting matrix are approximated by $z_{i j}\left(1-z_{i j}\right)$, as suggested by Angelini and De Angelis (2019).

The betting market is efficient according to the following sufficient condition, or null hypothesis, $H_{0}: \beta_{h}=\beta_{a}=\beta_{z}=0$. If we find that estimates of $\beta_{h}, \beta_{a}$ or $-\left(\beta_{h}+\beta_{a}\right)$ are significantly positive or negative, then this would imply that home, away or draw results are under- or over-predicted by bookmaker odds, respectively. Similarly, a positive estimate of $\beta_{z}$ would be consistent with a favourite-longshot bias being prevalent in market prices. Crucially, we estimate standard errors which are robust to clusters at the match level, as $\varepsilon_{i j}$ will be highly correlated over bookmakers and outcomes for any given match. Not addressing this, or clustering in some other inappropriate dimension, such as at the bookmaker level, will lead to spuriously precise estimates and possible false rejection of the null hypothesis. ${ }^{1}$

We also test whether the information contained in linear combinations of odds from other bookmakers $k=1, \ldots, J-1 \neq j$ can significantly explain $\varepsilon_{i}$ for any given bookmaker $j$. To do so, we apply the forecast encompassing method of Chong and Hendry (1986), estimating $J$ regressions using least squares, i.e. for each bookmaker $j$ :

$\varepsilon_{i j}=\alpha_{j}+\beta_{h j} h_{i j}+\beta_{a j} a_{i j}+\beta_{z j} z_{i j}+\sum_{\substack{k=1 \\ k \neq j}}^{J-1} \beta_{k j} z_{i k}+\phi_{t(i) j}+\eta_{i j}, \quad E\left[\eta_{i j} \mid \alpha_{j}, h_{i j}, a_{i j}, z_{i j}, z_{i, k \neq j}, \phi_{t j}\right]=0$.

Under the null hypothesis that an individual bookmaker $j$ operates an efficient market, $H_{0}: \beta_{1 j}=\ldots=\beta_{J-1, j}=0$. If we find that the linear combination of other bookmakers' odds significantly explains another bookmaker's values of $\varepsilon_{i j}$, then the odds of the latter are not taking into account relevant information, and this bookmaker cannot be operating an efficient market.

\section{Data and Results}

Results of the four leading English professional leagues, Premier League (PL), Championship (CH), League One (L1) and League Two (L2), were collected for the 2010/11 to 2017/18 seasons from Soccerbase.com. There were 16,407 matches: 3,039 in the PL; and 4,456 in each of the other leagues. Online betting odds from immediately before each match began and for each result outcome were extracted from Oddsportal.com for fifty-one bookmakers. ${ }^{2}$ Relevant

\footnotetext{
${ }^{1}$ In practice, almost all the variance in the estimated residuals is between match-outcomes rather than within, i.e. $\operatorname{var}_{i j}\left(\widehat{\widehat{v}}_{i}\right) / \operatorname{var}_{i j}\left(\widehat{v}_{i j}\right)>0.999$, where $\bar{v}_{i}$ is the mean estimated residual of match-outcome $i$.

${ }^{2}$ Oddsportal.com also collect odds, and associated betting volumes for a small number of betting exchanges. These enable us to check the relative importance in terms of betting volumes of the different divisions in English
} 
sample descriptive statistics over all matches and bookmakers are presented by Table 1 . The overround is smaller for higher leagues in the hierarchy, perhaps reflecting that these betting markets are more competitive. Similarly, match outcomes appear to be more predictable in the Premier League than in the other divisions, indicated in the former by a lower mean squared error for the bookmakers' odds-implied forecasts. The matched panel of odds and matches is unbalanced, since not all bookmakers set odds for each match. The coverage of these bookmakers over matches was increasingly complete over the seasons, most likely reflecting the increasing competition and globalisation of online betting markets. In what follows, we focus on a reduced sample of thirteen bookmakers. These were selected using an arbitrary rule, whereby they set odds for at least $90 \%$ of the matches taking place in every season and each league. We check whether our findings generalise to the larger sample of fifty-one bookmakers.

To begin, we focus on the PL market, estimating variants of Equation (1). The results are summarised in Table 2. Column (I) shows results from estimating the regression model excluding the favourite-longshot bias term. The negative signs of $\widehat{\beta}_{h}$ and $\widehat{\beta}_{a}$ suggest home and away wins are over-predicted, relative to the draw: the odds implied forecast error is on average 1.7 percentage points less for an away win, and bookmakers are less successful at predicting the draw, as previously suggested by Pope and Peel (1989). However, there is no statistically significant evidence at standard levels (5\% or $1 \%$ level, two-tailed tests) that bookmaker odds excessively price in any particular match result outcomes. This is consistent with the small sample fixed odds evidence from Kuypers (2000). Column (II) considers the favourite-longshot bias only. The estimates imply that for every 10 percentage points increase in the outcome forecast probability the bookmaker error on average reduces by 0.0012 , i.e. bookmakers underestimate the longshot rather than the most likely outcome, which is the opposite direction in which this bias is normally expected to occur. Angelini and De Angelis (2019) found a smaller magnitude but positive estimate for favourite-longshot bias for the Premier League, though in both our and their cases, the estimates are not statistically significant at standard levels. Columns (III) and (IV) estimate Equation (1) looking at both potential sources of inefficiency, for the selected thirteen bookmakers and the larger set of fifty-one, respectively. There is no evidence in any of these estimates to reject the null hypothesis, at standard levels of significance, that the PL results betting market has been efficient over the past eight seasons.

Table 3 presents equivalent estimates of Equation (1) for each division as per Column (III) of Table 2, with the PL results included again for comparison. In each of the leagues over this period, there is no significant evidence to reject the EMH in this context, despite apparently large positive coefficient estimates on the favourite-longshot effects in the Championship and

football. On average volumes are much larger in the PL (mean $£ 23,262$, median $£ 10,111$ ) than in the $\mathrm{CH}$ (mean $£ 3,044$, median $£ 1,540$ ), L1 (mean $£ 1,030$, median £616) or L2 (mean £878.20, median $£ 559$ ). 
League 2. We also estimate this preferred specification of the model for each league and within each season. We summarise these results in Figure 1, which displays the $p$-values for the $F$-tests of the sufficient conditions for each betting market being efficient in a season. There appears to be no pattern over time or divisions in the extent to which the online betting markets were generally efficient. If we were to focus on the low $p$-values, then we could conclude that on occasion the markets did display significant bias and inefficiency, for example the Premier League in 2010, but these examples occur no more frequently than natural randomness and variation in match outcomes would imply. In the language of the Mincer and Zarnowitz (1969) forecast efficiency framework, the online odds over this period give unbiased forecasts of football match outcomes and are generally efficient, subject to the bookmaker's rate of commission. ${ }^{3}$ In our view, this provides more convincing and general evidence than most of the previous studies addressing this issue, since they were either based on very small samples, ignored the draw outcome or only studied average market odds.

Competition in betting markets has been increasing as transaction costs have fallen and the industry has increasingly moved online (Forrest, 2008). In this case, we would expect the average commission rate to be decreasing. Figure 2 plots the time series of commission rates implied by values of $\widehat{\phi}_{t}$ for each division, using the model estimates from Table 3 . In all four divisions and for the fixed sample of 13 bookmakers, commission rates significantly decreased by $0.3-0.5$ points by the end of the 2017/18 season. Previous findings, however, suggest that bookmaker commission rates have been broadly constant in England despite the hypothesised increasing commercial pressure (Forrest et al., 2005; Angelini and De Angelis, 2019). A simple reason our results may differ is that we fix the bookmakers studied over the sample period, and therefore the estimated commission rates are not impacted by changes in the sample composition, e.g. small new entrants with generally less competitive odds.

Finally, we estimate Equation (2) for each of the thirteen bookmakers in the reduced sample over all divisions, sample years and match outcomes, covering the 12,855 matches where all set odds, and testing whether a linear combination of the odds from the other 12 bookmakers can significantly help to predict $\varepsilon_{i j}$. Table 4 summarises these results by displaying the $p$-values for the relevant $F$-tests tests for each bookmaker in Column (I). ${ }^{4}$ We find that for most bookmakers a linear combination of the odds from competitors in the market would significantly predict their own odds-implied forecast errors. In this way, we can reject the EMH for eight of the thirteen bookmakers at the $0.1 \%$ level, eight at the $1 \%$ level, and twelve at the

\footnotetext{
${ }^{3}$ Strong-form efficiency would dictate that there is no information not currently in the bookmaker's information set which could predict the odds-based forecast errors (Nordhaus, 1987).

${ }^{4} \mathrm{We}$ do not display the other estimated model coefficient estimates as these are by construction identical across individual bookmaker regressions, affected by significant multicollinearity and uninteresting, and insignificant as per the general results.
} 
5\% level of significance. The betting prices set by individual bookmakers for English football match results do not incorporate readily available and timely information which can be used to forecast the event outcomes. However, this information also accounts for a tiny fraction of the overall variation in forecast errors, accounting for at most $0.1 \%$ for any one of the thirteen bookmakers (Column (II), Table 4). In other words, the increases in market efficiency should each bookmaker incorporate each other's odds may be statistically significant but in magnitude are almost certainly tiny. This may reflect the fact that there are small economic costs faced by bettors who seek out the best odds on an outcome, for example due to the time taken to switch funds and attention between online accounts.

\section{Conclusion}

In this article, we have added new evidence on whether betting markets are efficient. At the overall market level, we found no statistically significant evidence which could reject an efficient market hypothesis for the online betting market for English football match results. The odds offered by bookmakers were generally not biased towards any particular result outcome, nor did they feature the favourite-longshot bias, which has been documented in other betting markets. But individual bookmaker-specific markets were not efficient, since they failed to use the information contained in their competitors' odds, though these effects were very small. There is also suggestive evidence that the increased competition facing online bookmakers has reduced commission rates and profit margins. 


\section{References}

Angelini, G., and L. De Angelis. 2019. "Efficiency of online football betting markets." International Journal of Forecasting, 35(2): 712 - 721.

Chong, Y. Y., and D. Hendry. 1986. "Econometric evaluation of linear macro-economic models." Review of Economic Studies, 53(4): 671-690.

Fama, E. F. 1970. "Efficient Capital Markets: A Review of Theory and Empirical Work." Journal of Finance, 25(2): 383-417.

Forrest, D. 2008. "Soccer Betting in Britain.” In Handbook of Sports and Lottery Markets. Eds. by D. B. Hausch, and W. T. Ziemba, San Diego Elsevier, 421 - 446.

Forrest, D., J. Goddard, and R. Simmons. 2005. “Odds-setters as forecasters: The case of English football.” International Journal of Forecasting, 21(3): 551-564.

Goddard, J., and I. Asimakopoulos. 2004. "Forecasting football results and the efficiency of fixed-odds betting." Journal of Forecasting, 23(1): 51-66.

Kuypers, T. 2000. "Information and efficiency: an empirical study of a fixed odds betting market." Applied Economics, 32(11): 1353-1363.

Levitt, S. D. 2004. "Why are gambling markets organised so differently from financial markets?" The Economic Journal, 114(495): 223-246.

Mincer, J., and V. Zarnowitz. 1969. "The evaluation of economic forecasts." In Economic Forecasts and Expectations: Analysis of Forecasting Behavior and Performance. NBER, 1-46.

Na, S., Y. Su, and T. Kunkel. 2018. "Do not bet on your favourite football team: the influence of fan identity-based biases and sport context knowledge on game prediction accuracy." European Sport Management Quarterly, 0(0): 1-23.

Nordhaus, W. D. 1987. "Forecasting Efficiency: Concepts and Applications." The Review of Economics and Statistics, 69(4): 667-674.

Ottaviani, M., and P. N. Sørensen. 2008. "The Favorite-Longshot Bias: An Overview of the Main Explanations." In Handbook of Sports and Lottery Markets. Eds. by D. B. Hausch, and W. T. Ziemba, San Diego Elsevier, 83 - 101.

Pope, P. F., and D. A. Peel. 1989. "Information, Prices and Efficiency in a Fixed-Odds Betting Market." Economica, 56(223): 323-341.

Reade, J. J. 2014. "Information and predictability: Bookmakers, prediction markets and tipsters as forecasters." The Journal of Prediction Markets, 8(1): 43-76.

Thaler, R., and W. T. Ziemba. 1988. "Parimutuel Betting Markets: Racetracks and Lotteries." Journal of Economic Perspectives, 2(2): 161-74.

Vlastakis, N., G. Dotsis, and R. N. Markellos. 2009. "How efficient is the European football betting market? Evidence from arbitrage and trading strategies." Journal of Forecasting, 28(5): 426-444. 
TABLE 1: Sample descriptive statistics of match outcomes and bookmaker odds by division, over all matches and bookmakers, 2010/11-2017/18

\begin{tabular}{lcccc}
\hline & $\begin{array}{c}\text { PL } \\
(\text { I) }\end{array}$ & $\begin{array}{c}\text { CH } \\
(\text { II) }\end{array}$ & $\begin{array}{c}\text { L1 } \\
(\text { III })\end{array}$ & $\begin{array}{c}\text { L2 } \\
(\text { IV })\end{array}$ \\
\hline Share of home wins $-h$ & 0.455 & 0.432 & 0.429 & 0.432 \\
Share of away wins $-a$ & 0.293 & 0.294 & 0.304 & 0.315 \\
Mean overround $-\kappa$ & 0.048 & 0.062 & 0.071 & 0.072 \\
Mean absolute error $-|\varepsilon|$ & 0.385 & 0.423 & 0.426 & 0.430 \\
Mean squared error $-\varepsilon^{2}$ & 0.190 & 0.208 & 0.210 & 0.212 \\
\hline Matches: $I$ & 3,039 & 4,456 & 4,456 & 4,456 \\
Bookmakers: $J$ & 51 & 49 & 49 & 49 \\
\hline
\end{tabular}

TABLE 2: Model estimates and tests of betting market efficiency for English Premier League match results, 2010/11-2017/18

\begin{tabular}{rcccc}
\hline & $(\mathrm{I})$ & $(\mathrm{II})$ & $(\mathrm{III})$ & $(\mathrm{IV})$ \\
\hline Home win: $\widehat{\beta}_{h}$ & -0.007 & & -0.006 & -0.003 \\
& $(0.015)$ & & $(0.016)$ & $(0.017)$ \\
Away win: $\widehat{\beta}_{a}$ & -0.017 & & -0.016 & -0.015 \\
& $(0.014)$ & & $(0.014)$ & $(0.014)$ \\
Inverse odds: $\widehat{\beta}_{z}$ & & -0.012 & -0.006 & 0.000 \\
& & $(0.035)$ & $(0.038)$ & $(0.039)$ \\
\hline$F$-test: $\widehat{\beta}_{h}, \widehat{\beta}_{a}, \widehat{\beta}_{z}$ & & & 0.703 & 0.747 \\
$F$-test: $-\left(\widehat{\beta}_{h}+\widehat{\beta}_{a}\right)$ & 0.338 & & 0.386 & 0.481 \\
$F$-test: $\widehat{\phi}_{t}$ & 0.005 & 0.006 & 0.005 & 0.000 \\
Bookmaker FEs: $\widehat{\alpha}_{j}$ & No & Yes & Yes & Yes \\
Mean dependent variable: $\bar{\varepsilon}$ & -0.015 & -0.015 & -0.015 & -0.016 \\
\hline Bookmakers: $J$ & 13 & 13 & 13 & 51 \\
Odds: $N$ & 117,285 & 117,285 & 117,285 & 325,644 \\
\hline
\end{tabular}

Notes: First $F$-test shows $p$-values of the restriction $H_{0}: \beta_{h}=\beta_{a}=\beta_{z}=0$. Second $F$-test shows $p$-values of the restriction $H_{0}: \beta_{d}=-\left(\beta_{h}+\beta_{a}\right)=0$. Third $F$-test shows $p$-value of the restriction $H_{0}: \phi_{2010}=\cdots=\phi_{2017}=0$. Column (I) shows estimates of Equation (1) on the reduced sample of 13 bookmakers, without the bookmaker fixed effects and the favourite-long-shot bias term.

Column (II) shows estimates of Equation (1) without the result bias effects and adding the bookmaker fixed effects and the favourite-long-shot bias term to Column (I), which is the specification here most comparable with Angelini and De Angelis (2019).

Column (III) adds the result bias effects to Column (II), and estimates Equation (1) as written for the reduced sample.

Column (IV) is equivalent to Column (III), except it is for the full sample of 51 bookmakers.

Estimated standard errors in parentheses are robust to clusters at the match level, following weighted least squares, with weights approximated by $z_{i j}\left(1-z_{i j}\right)$. 
TABLE 3: Estimates and tests of betting market efficiency in English professional football: comparison of preferred model over divisions, 2010/11-2017/18

\begin{tabular}{rcccc}
\hline & $\begin{array}{c}\text { PL } \\
(\mathrm{I})\end{array}$ & $\begin{array}{c}\text { CH } \\
(\mathrm{II})\end{array}$ & $\begin{array}{c}\text { L1 } \\
(\mathrm{III})\end{array}$ & $\begin{array}{c}\text { L2 } \\
(\mathrm{IV})\end{array}$ \\
\hline Home win: $\widehat{\beta}_{h}$ & -0.006 & -0.015 & 0.001 & -0.014 \\
& $(0.016)$ & $(0.015)$ & $(0.014)$ & $(0.015)$ \\
Away win: $\widehat{\beta}_{a}$ & -0.016 & 0.003 & 0.010 & 0.010 \\
& $(0.014)$ & $(0.011)$ & $(0.011)$ & $(0.012)$ \\
Inverse odds: $\widehat{\beta}_{z}$ & -0.006 & 0.052 & -0.007 & 0.034 \\
& $(0.038)$ & $(0.055)$ & $(0.055)$ & $(0.061)$ \\
\hline$F$-test: $\widehat{\beta}_{h}, \widehat{\beta}_{a}, \widehat{\beta}_{z}$ & 0.703 & 0.674 & 0.814 & 0.428 \\
$F$-test: $-\left(\widehat{\beta}_{h}+\widehat{\beta}_{a}\right)$ & 0.386 & 0.558 & 0.609 & 0.876 \\
$F$-test: $\widehat{\phi}_{t}$ & 0.005 & 0.000 & 0.012 & 0.001 \\
Bookmaker FEs: $\widehat{\alpha}_{j}$ & Yes & Yes & Yes & Yes \\
Mean dependent variable: $\bar{\varepsilon}$ & -0.015 & -0.018 & -0.021 & -0.021 \\
\hline Bookmakers: $J$ & 13 & 13 & 13 & 13 \\
Odds: $N$ & 117,285 & 170,760 & 168,615 & 169,677 \\
\hline
\end{tabular}

Notes: See Table 2. Columns (I)-(IV) estimate the same specification as Column (III) in Table 2, except here Equation (1) is estimated for each division separately.

Estimated standard errors in parentheses are robust to clusters at the match level, following weighted least squares, with weights approximated by $z_{i j}\left(1-z_{i j}\right)$. 
TABLE 4: Tests of individual bookmaker market efficiency, all divisions 2010/11-2017/18: do other bookmakers' odds add information?

\begin{tabular}{lcc}
\hline Bookmaker $(j)$ & $\begin{array}{c}F \text {-test: } \widehat{\beta}_{k j} \\
(\mathrm{I})\end{array}$ & $\begin{array}{c}\text { Share of } \operatorname{var}_{i}\left(\varepsilon_{i j}\right) \\
(\text { II) }\end{array}$ \\
\hline 10Bet & 0.0012 & 0.0001 \\
12Bet & 0.0035 & 0.0003 \\
188BET & 0.0000 & 0.0005 \\
5Dimes & 0.0200 & 0.0002 \\
BetVictor & 0.0000 & 0.0003 \\
Jetbull & 0.0000 & 0.0002 \\
Leonbets & 0.1185 & 0.0001 \\
Pinnacle & 0.0099 & 0.0001 \\
SBOBET & 0.0000 & 0.0011 \\
Titanbet & 0.0001 & 0.0001 \\
William Hill & 0.0000 & 0.0007 \\
bet365 & 0.0361 & 0.0001 \\
youwin & 0.0000 & 0.0002
\end{tabular}

Odds: $N$ 38,655

Notes: $F$-test shows $p$-value for each bookmaker $j$ of the test for $H_{0}: \beta_{1 j}=\ldots=\beta_{J-1, j}=0$, as per Equation (2). Estimated using weighted least squares, with weights approximated by $z_{i j}\left(1-z_{i j}\right)$.

Column (2) shows the share of the variance in the dependent variable of Equation (2) (forecast errors) that can be accounted for by the estimated linear combination of the other 12 bookmakers' odds, i.e. $\operatorname{covar}_{i}\left(\varepsilon_{i j}, \sum_{\substack{k=1 \\ k \neq j}}^{J-1} \widehat{\beta}_{k j} z_{i k}\right) / \operatorname{var}_{i}\left(\varepsilon_{i j}\right)$. 
FIGURE 1: Betting market efficiency test $p$-values by division and season

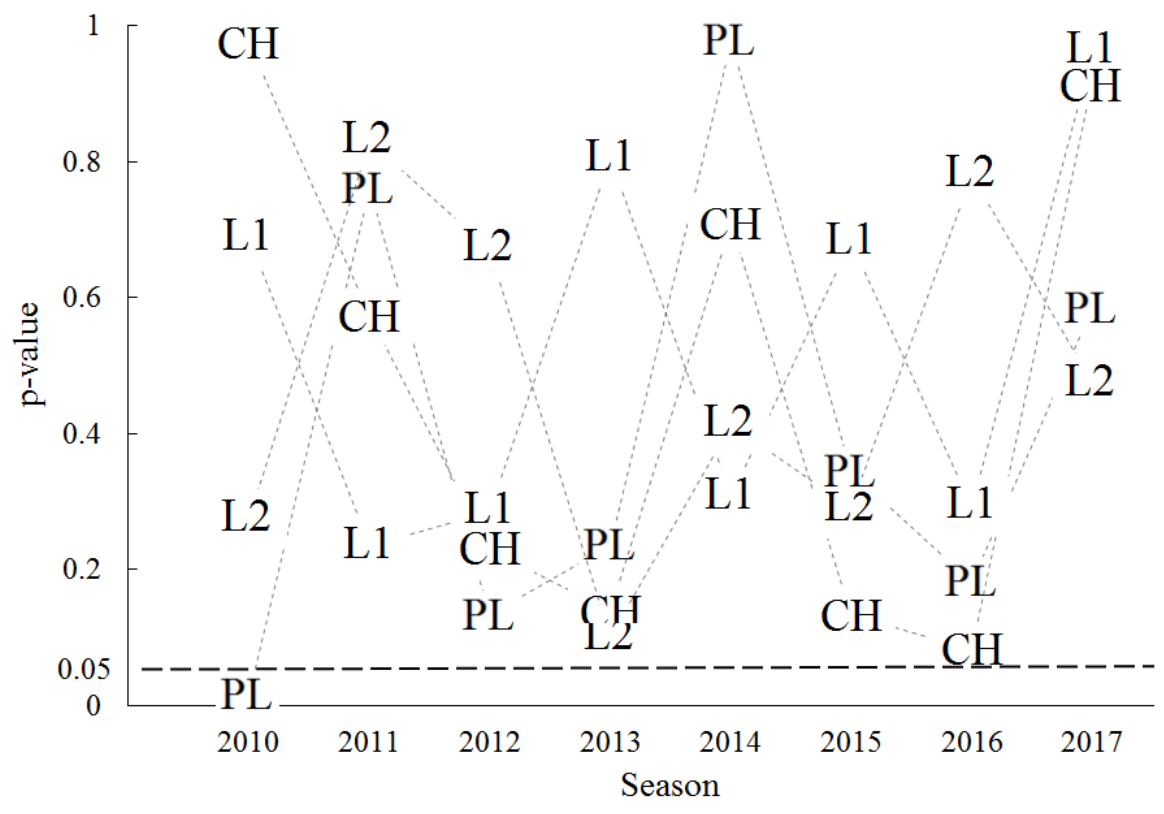

Notes.- shows $p$-values of the $F$-test for restriction $H_{0}: \beta_{h}=\beta_{a}=\beta_{z}=0$, for estimates of Equation (1) by division and season for the reduced sample of 13 bookmakers. 
FIGURE 2: Estimated bookmaker commission rates on markets since the 2010/11 season

(a) Premier League

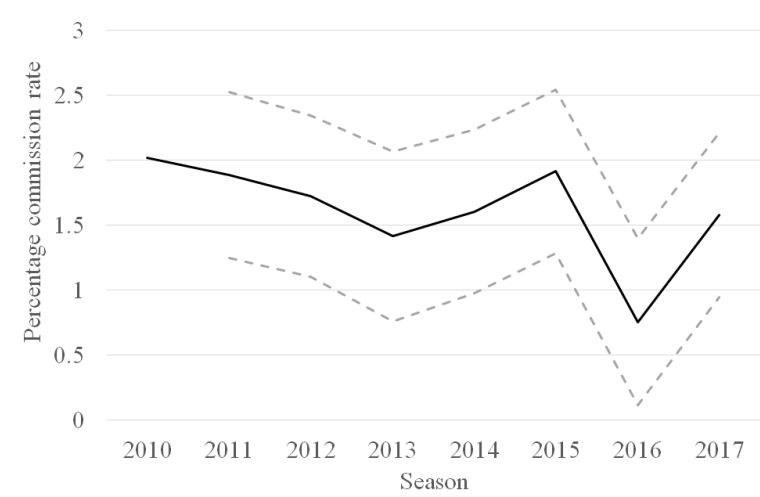

(c) League 1

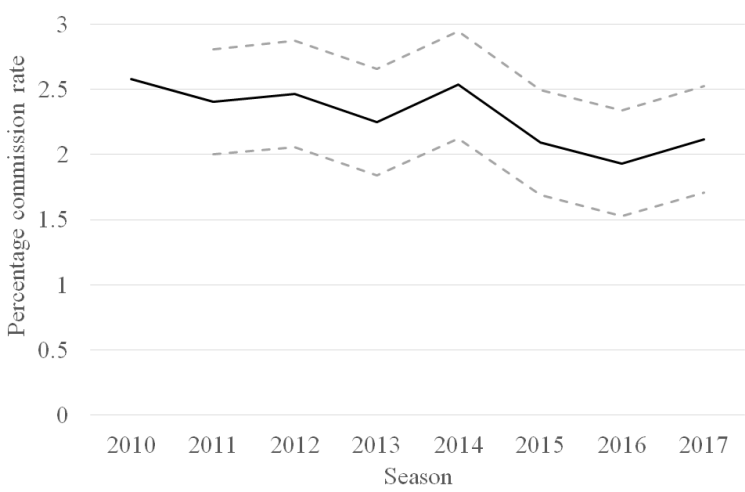

(b) Championship

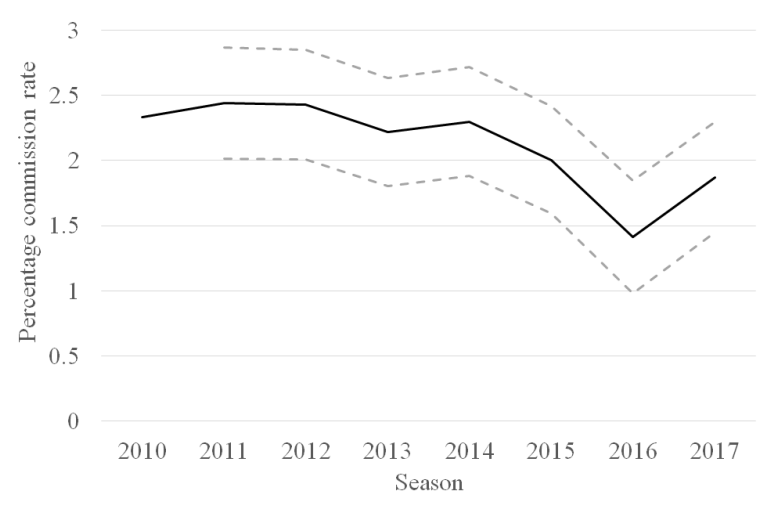

(d) League 2

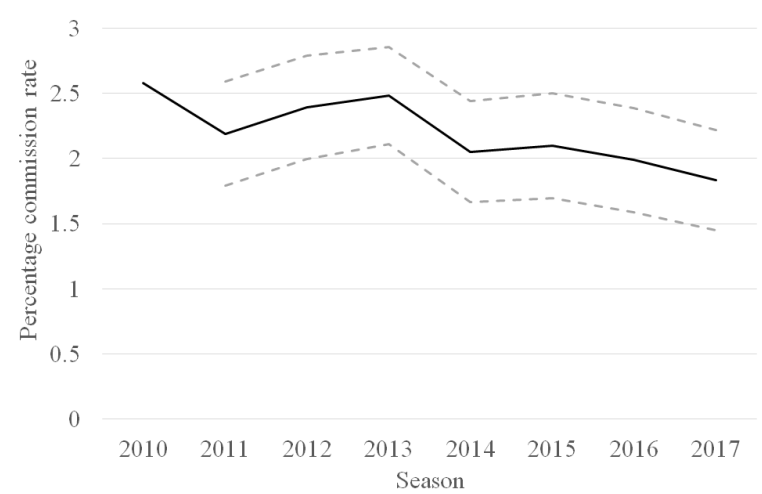

Notes: dashed lines indicate 95\% confidence intervals of the differences from the 2010/11 season, estimated with standard errors robust to clusters at the match level. 